\title{
Transmission and Consumption of Air Power in Pneumatic System
}

\author{
Shengzhi Chen ${ }^{1}$, Chongho Youn ${ }^{2}$, Toshiharu Kagawa², Maolin Cai ${ }^{3}$ \\ ${ }^{1}$ Department of Mechano-Micro Engineering, Tokyo Institute of Technology, Kanagawa, Japan \\ ${ }^{2}$ Interdisciplinary Graduate School of Science and Engineering, Tokyo Institute of Technology, Kanagawa, Japan \\ ${ }^{3}$ School of Automation Science and Electrical Engineering, Beihang University, Beijing, China \\ Email: chen.s.af@m.titech.ac.jp
}

Received 17 August 2014; revised 15 September 2014; accepted 5 October 2014

Copyright (C) 2014 by authors and Scientific Research Publishing Inc.

This work is licensed under the Creative Commons Attribution International License (CC BY).

http://creativecommons.org/licenses/by/4.0/

(c) (i) Open Access

\section{Abstract}

In recent 20 years, energy saving has been done in many projects. However, in pneumatic system, it is not easy to determine or measure the air power flow because of the compressibility of pneumatic system. In this paper, we used air power meter (APM) to measure the energy consumption of flow in pneumatic cylinder actuator system. Meter-in circuit and meter-out circuit of speed control system are used in this research. The model of cylinder system is based on four equations: state equation of air, energy equation, motion equation and flow equation. The model estimates the pressure change in charge and discharge side of cylinder, and also the displacement and velocity of the piston. Furthermore, energy consumption could theoretically be calculated when the change of air state is regarded as isothermal change. Lastly, some data of these two circuits are shown, and the consumption of energy is discussed.

\section{Keywords}

\section{Air Power, Meter-In Circuit, Meter-Out Circuit, Energy Consumption}

\section{Introduction}

Pneumatic cylinder actuator is widely used in factory automation field as a driving machine. To compare with the electrical motor, it is commonly used for conveying system because of its advantage of reciprocal linear motion. Furthermore, in meter-out circuit, the most remarkable characteristic is the response of speed control becomes stable easily when adjusting the speed control valve. Recently, PTP (Point To Point) is a representative application in the industry field. In these ten years, the development of pneumatic technology has become better due to the widely use of the pneumatic cylinder. 
As we know, the power of compressed air used for mechanical work is based on the electricity consumption of compressor. The energy saving in pneumatic system is important. So many methods had been proposed [1]. In order to achieve the effective use of available energy, the assessment of energy consumption is necessary. Previous research showed that the available energy of air consists of two parts: power transmission energy and expansive energy [2]. It is clarified that over half of supplied available energy is used and remaining energy is lost [3]. However, the measurement of the consumption of available energy in a pneumatic cylinder system has not been conducted. The reason is that there are not any effective methods to measure the energy. To compare with the traditional energy consumption assessment method based on air flow rate, a new method using air power in terms of available energy has been proposed [4]. With air power, mechanism and factors will make objective of energy savings clearly.

In this paper, we use APM (Air Power Meter) to measure the energy consumption of the pneumatic cylinder based on meter-in and meter-out circuit, and the experimental results will be discussed.

\section{Circuit of Speed Control}

In general, the speed control of the pneumatic cylinder is controlled by a speed-control valve which is consisted of a variable throttle valve and a check valve. In term of the adjustment of the charging or discharging flow when using the speed-control valve, the meter-in and meter-out circuit have the different characteristics. As shown in Figure 1, the meter-in circuit could control the speed of the pneumatic cylinder by varying the charging flow. Figure 2 is a schematic of meter-out circuit which is controlled by varying the discharging flow. To compare with the meter-out circuit, meter-in circuit has two advantages as follows. Assume that these two circuits are driven in the same conditions of the supply pressure and load mass. One advantage is the miniaturization of machine and another one is the less consumption of air.

However, meter-out circuit is more popular than meter-in circuit. Many pneumatic mechanism makers recommend people to use meter-out circuit expect for the particular situation. We consider that the reason is the simplification and stability of the speed control. The simplification indicates that the setting of speed is easily because of the speed is proportional to the regulated size of the speed-control valve. And the stability indicates that the speed response is not relevant to the load mass. That is, the speed response reaching to steady-state is independent on the change of load mass.
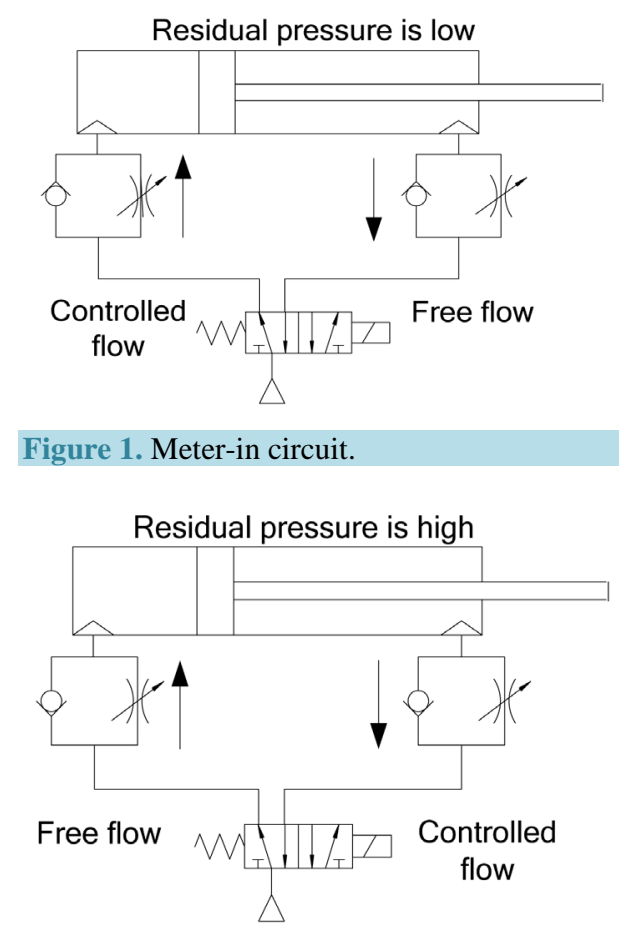

Figure 2. Meter-out circuit. 
In addition, two merits of the meter-out circuit are described below.

One is the initial acceleration is very small because of the backpressure in discharge side, so that the piston will not move quickly. Another one is the cushion in the end part of the cylinder could play an important role due to the constant value of the pressure in discharge side.

\section{Equations of Pneumatic System}

The circuit of pneumatic system is shown in Figure 3. Four basic equations are shown as follows.

\subsection{State Equation}

When we derivative the state equations of air $(P V=m R \theta)$ in charge side and discharge side, the following equations are obtained. Here, $P$ is pressure; $u$ is velocity of flow; $S$ is pressured area; $\theta$ is temperature. And $V$ represents volume; $R$ represents gas constant of air; $G$ represents mass flow rate. The subscript $c$ and $d$ refer to the charge side and discharge side, respectively.

$$
\begin{aligned}
& V_{c} \frac{\mathrm{d} P_{c}}{\mathrm{~d} t}=-S_{c} P_{c} u+R \theta_{c} G_{c}+\frac{P_{c} V_{c}}{\theta_{c}} \frac{\mathrm{d} \theta_{c}}{\mathrm{~d} t} \\
& V_{d} \frac{\mathrm{d} P_{d}}{\mathrm{~d} t}=S_{d} P_{d} u+R \theta_{d} G_{d}+\frac{P_{d} V_{d}}{\theta_{d}} \frac{\mathrm{d} \theta_{d}}{\mathrm{~d} t}
\end{aligned}
$$

\subsection{Energy Equation}

Assuming that the value of heat transfer coefficient is constant, from the conservation of energy and the state equations of air, we obtain the following equations:

$$
\begin{gathered}
\frac{C_{v} P_{c} V_{c}}{R \theta_{c}} \frac{\mathrm{d} \theta_{c}}{\mathrm{~d} t}=C_{v} G_{u}\left(\theta_{a}-\theta_{c}\right)+R \theta_{a} G_{c}-S_{c} P_{c} u+h_{c} S_{h c}\left(\theta_{a}-\theta_{c}\right) \\
\frac{C_{v} P_{d} V_{d}}{R \theta_{d}} \frac{\mathrm{d} \theta_{d}}{\mathrm{~d} t}=R \theta_{d} G_{d}+S_{d} P_{d} u+h_{d} S_{h d}\left(\theta_{a}-\theta_{d}\right)
\end{gathered}
$$

where $C_{v}$ represents the specific heat at constant volume, $h$ represents the heat transfer coefficient and $S_{h}$ is the heat transfer area.

\subsection{Motion Equation}

The friction of piston is given by

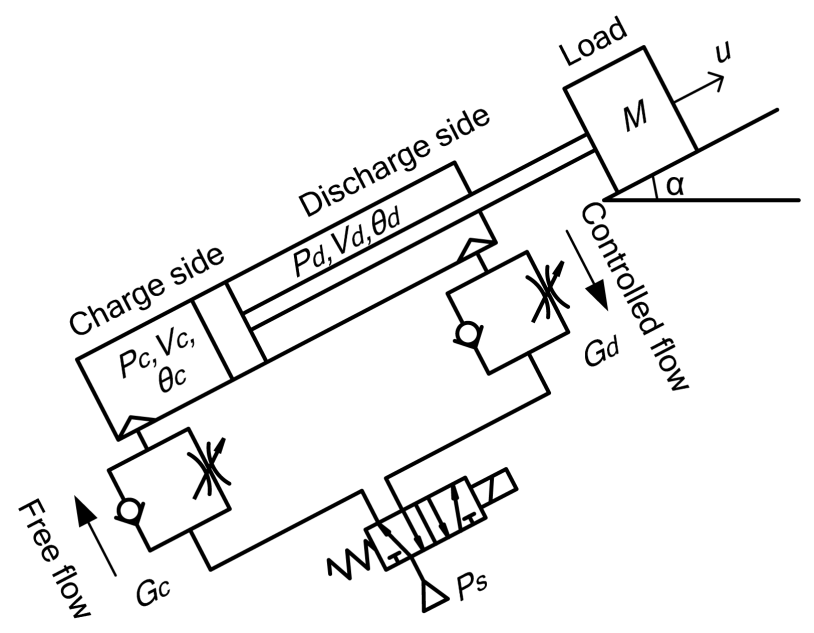

Figure 3. Meter-out circuit when driving a load. 


$$
F_{f}=\left\{\begin{array}{cc}
F_{s} & u=0 \\
F_{c}+C u & u \neq 0
\end{array}\right.
$$

So the motion equation of the piston is

$$
M \frac{\mathrm{d} u}{\mathrm{~d} t}=S_{c} P_{c}-S_{d} P_{d}-P_{a}\left(S_{c}-S_{d}\right)-F_{f}-M g \sin \alpha
$$

The atmosphere pressure is represented by $P_{a}$.

\subsection{Flow Equation}

The air mass flow for the charge and discharge side of the cylinder are expressed as

$$
\begin{gathered}
G_{c}=C_{c} P_{s} \rho_{0} \sqrt{\frac{\theta_{0}}{\theta_{a}}} \phi\left(P_{s}, P_{c}\right) \\
G_{d}=-C_{d} P_{d} \rho_{0} \sqrt{\frac{\theta_{0}}{\theta_{d}}} \phi\left(P_{d}, P_{a}\right)
\end{gathered}
$$

where the function $\phi$ is defined as

$$
\phi= \begin{cases}1 & P_{2} / P_{1} \leq b \\ \sqrt{1-\left(\frac{P_{2} / P_{1}-b}{1-b}\right)^{2}} & P_{2} / P_{1}>b\end{cases}
$$

$C$ is called as sonic conductance and $b$ represents the critical pressure ratio. Where $\rho_{o}$ refers to the air density and $\theta_{0}$ refers to the air temperature (ANR).

Using the equations above, we can calculate the pressure and temperature change in the cylinder chamber, also the displacement and velocity of piston.

\subsection{Energy Consumption}

As shown in Figure 4, we consider a pneumatic cylinder system which is driven in vertical with a load. When the load is lifted by piston, the cylinder chamber is full of the charging air. Assuming that the state change of air in cylinder is an isothermal change, the following equation is used to calculate the approximation of the energy consumption $E$ [5] [6].

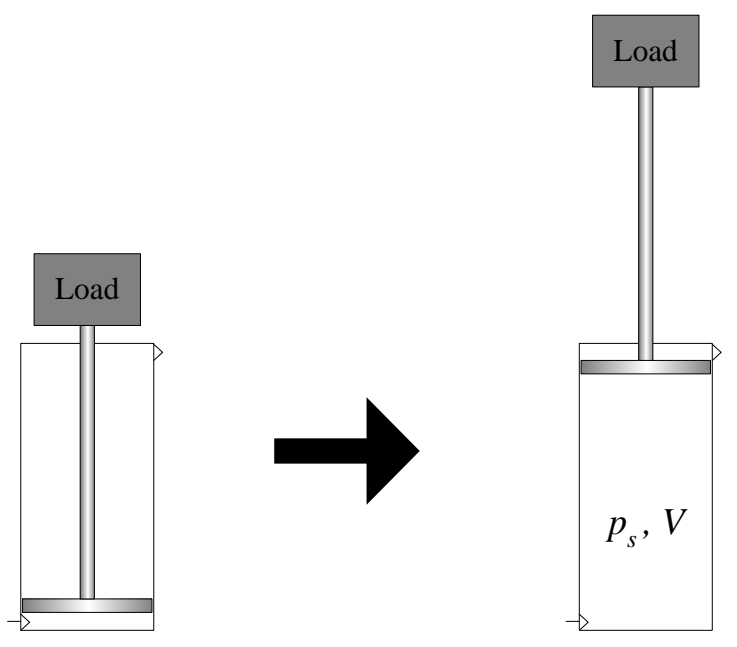

Figure 4. Energy consumption of cylinder. 


$$
E=P_{s} V \ln \left(\frac{P_{s}}{p_{a}}\right)
$$

From this equation, we can clarify that the energy consumption in this condition is only relevant to the supply pressure.

\section{Evaluation Experiment of Meter-Out Circuit}

Experimental apparatus is shown in Figure 5. A cylinder (MBF 40-200, SMC Co., Ltd.) of inner diameter 40 $\mathrm{mm}$ and stroke $200 \mathrm{~mm}$ was set up vertically and driven upwards. A load of mass $5 \mathrm{~kg} / 16 \mathrm{~kg}$ was set in the front head of the piston. And there is an orifice of diameter $0.4 \mathrm{~mm}$ at the discharge side of the cylinder.

A solenoid valve was used to control the air flow direction and a regulator was used to keep supply pressure constant and to vary the initial pressure. In order to measure the energy consumption of cylinder, we used air power meter (APM) which could measure the transient flow rate and air power at the charging side.

Before the experiment began, the charge chamber was set up to atmosphere pressure and discharge chamber was set up to supply pressure. Then, we opened the solenoid valve and began the experiment in different supply pressure.

At first, the result of the $P Q$ characteristics of orifice is shown in Figure 6. Here, the value of $C$ and $b$ are approximately $0.04 \mathrm{dm}^{3} /(\mathrm{s} \cdot \mathrm{bar})$ and 0.5 , respectively.

Secondly, the relationship between supply pressure and equilibrium velocity is shown in Figure 7. It can be seen that the equilibrium velocity become quickly with the increase of supply pressure. And then the velocity reaches to a constant value when supply pressure is higher than $350 \mathrm{kPa}$ (abs). This is an important characteristic of meter-out circuit because of the velocity of air is chocked.

Furthermore, the relationship between supply pressure and energy consumption is shown in Figure 8. As stated above, energy consumption is only relevant to the supply pressure when the load is driven by cylinder. It

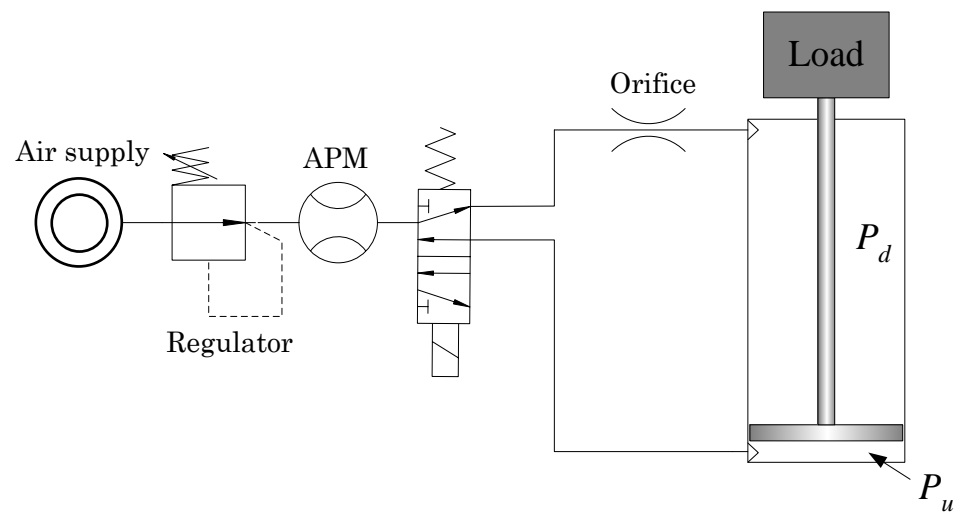

Figure 5. Meter-out circuit.

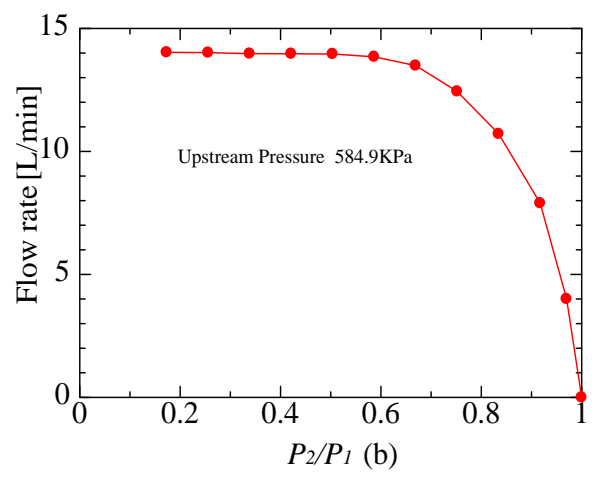

Figure 6. PQ characteristics of orifice. 


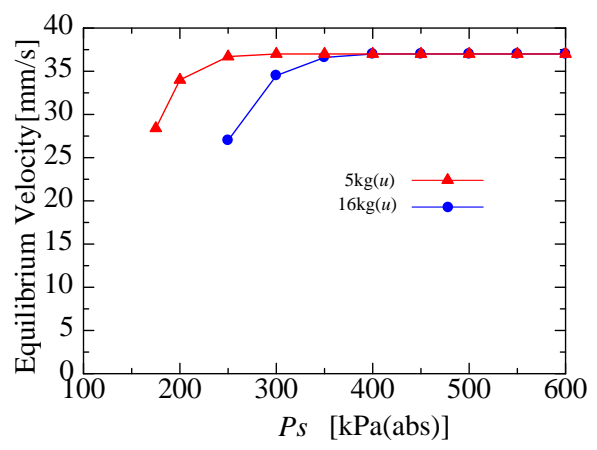

Figure 7. Relationship between supply pressure and equilibrium velocity.

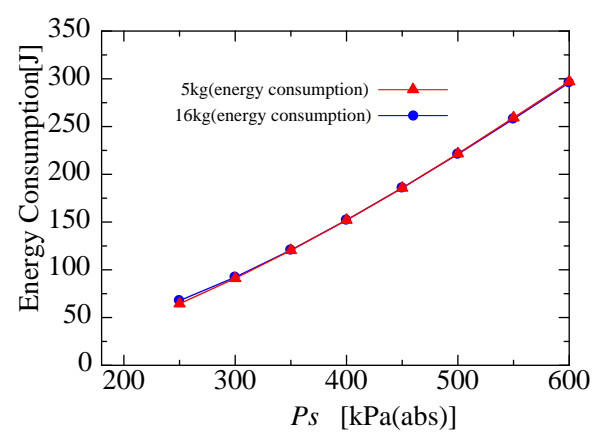

Figure 8. Relationship between supply pressure and energy consumption.

can be seen that the two curves of results in different condition are almost the same. It can be inferred that the energy consumption is increasing along with the supply pressure increased. In addition, we show the other experimental results in Figure 9 as a reference.

The result showed that when the supply pressure is set up to $600 \mathrm{kPa}$ (abs), the experimental result of energy consumption becomes $300 \mathrm{~J}$ during 6 seconds. On the other hand, from Equation (10) we obtained the theoretical result of energy consumption is $176 \mathrm{~J}$. That means, approximately $40 \%$ of energy is lost without being used in this experiment. We considered that the reasons are orifice, piston friction and acceleration.

Furthermore, when the supply pressure is set up to $300 \mathrm{kPa}$ (abs), the red line shows the power is approximately $15 \mathrm{~W}$. Then we used velocity of flow and flow rate to calculate the power used in the process of charging is $W=P Q=13.23 \mathrm{~W}$. Here, the velocity of flow is $35 \mathrm{~mm} / \mathrm{s}$. That means, over $80 \%$ of power is used for the control of velocity in meter-out circuit.

\section{Evaluation Experiment of Meter-In Circuit}

Experimental apparatus of meter-in circuit is shown in Figure 10. In this experiment, orifice was set up to the charge side. We use the same state equations and expression of energy consumption as in the meter-out circuit experiment. Experimental results in different conditions are shown in Figure 11. If supply pressure is low, the motion of piston reaches to an equilibrium velocity when the load is lifted. However, if supply pressure is too high, piston will move quickly due to the high-speed. We could not confirm that whether the motion of piston has reached to an equilibrium velocity or not. So we use the reaching time here instead of the velocity, and the relationship between reaching time and supply pressure is shown in Figure 12. It can be seen that the higher the supply pressure is, the shorter the reaching time is. In addition, Figure 13 shows the relationship between supply pressure and energy consumption, the trends of curves are the same as the results of meter-out circuit. We can use the expression (10) to calculate the approximation of the energy consumption $E$. Here, according to the same supply pressure and equation, we obtained the same theoretical result of energy consumption is $176 \mathrm{~J}$. The experimental result of energy consumption is $260 \mathrm{~J}$. That means, the ratio of the energy loss is approximately $32 \%$. 


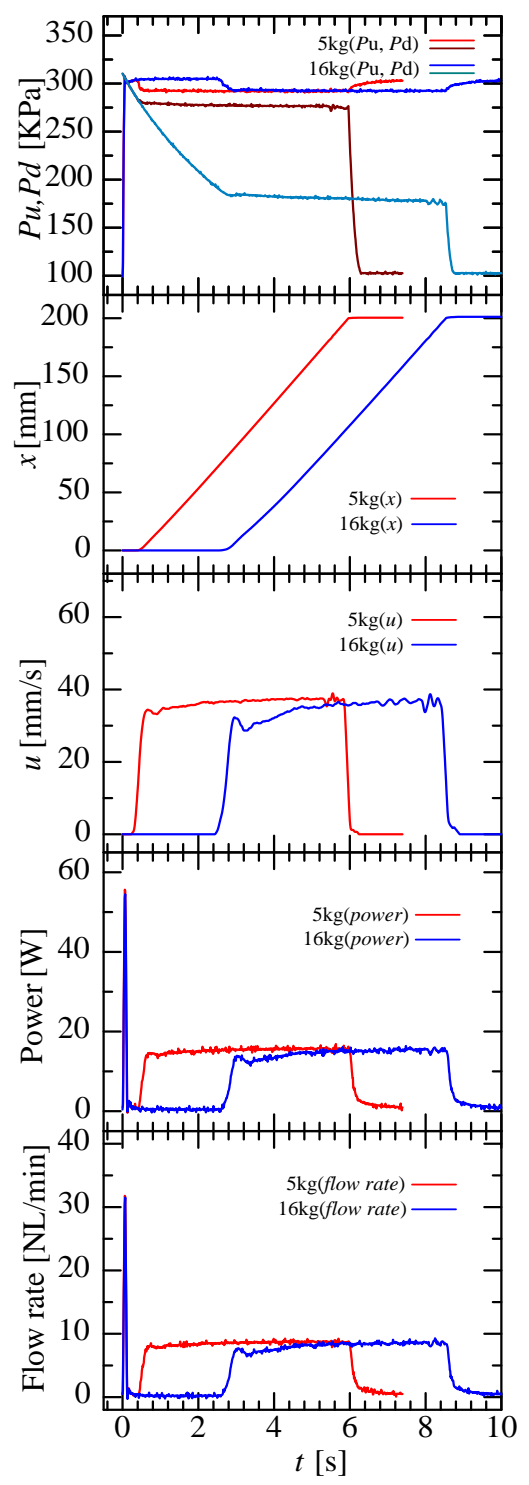

(a)

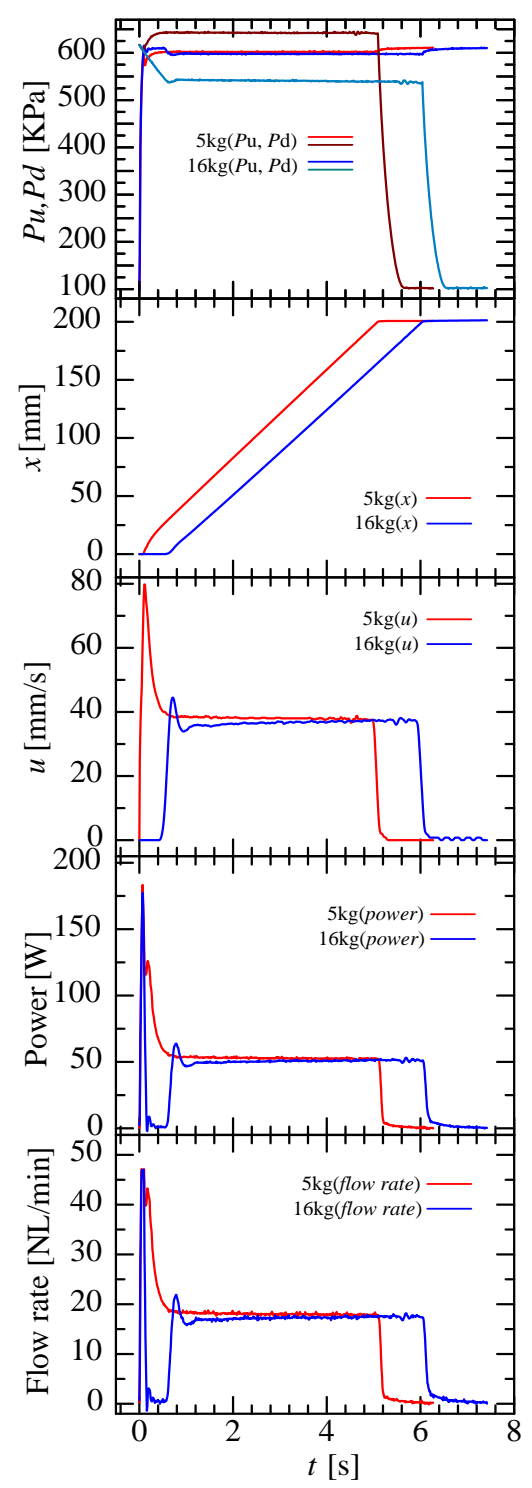

(b)

Figure 9. Experimental results of meter-out circuit. (a) $P_{s}=300 \mathrm{kPa}$ (abs); (b) $P_{s}=$ $600 \mathrm{kPa}(\mathrm{abs})$.

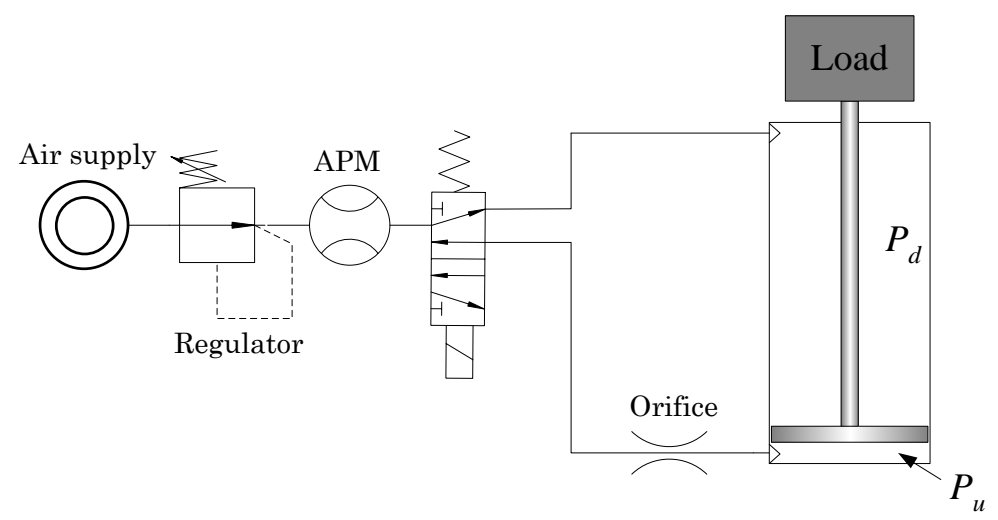

Figure 10. Meter-in circuit. 


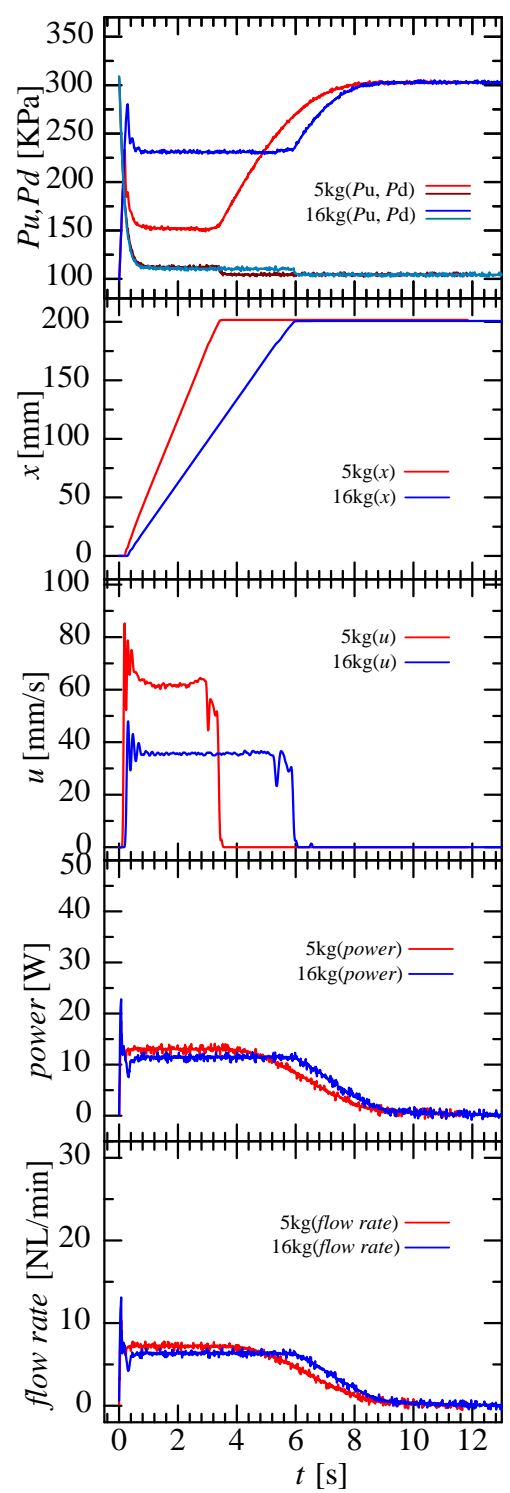

(a)

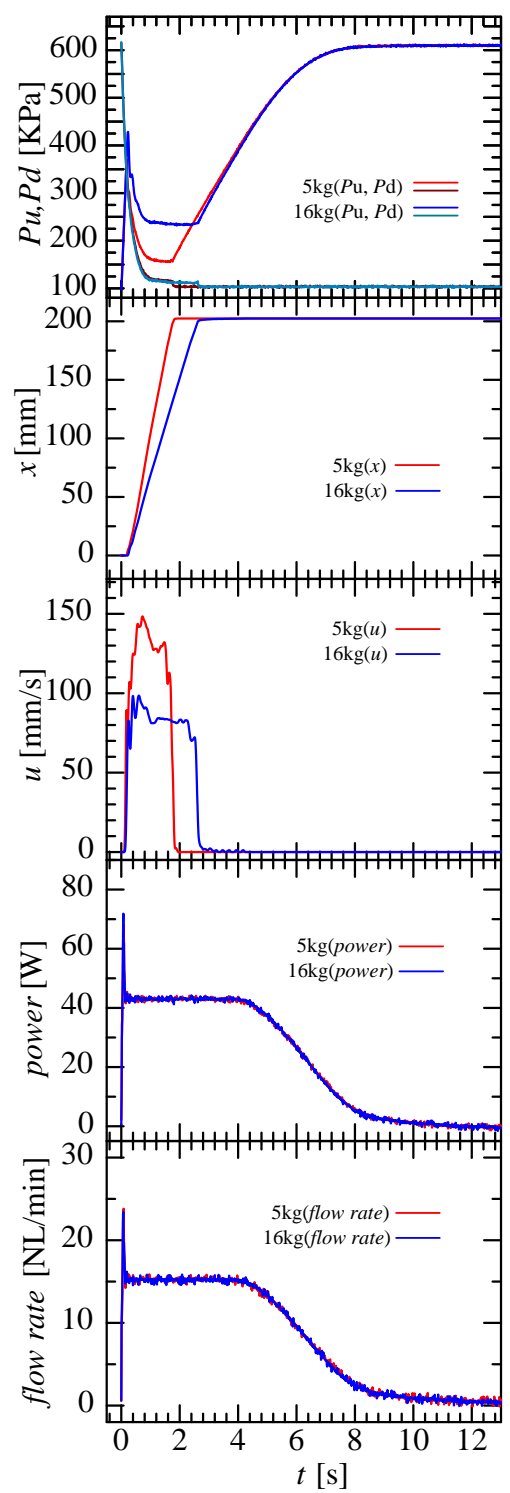

(b)

Figure 11. Experimental results of meter-in circuit. (a) $P_{s}=300 \mathrm{kPa}$ (abs); (b) $P_{s}=600$ kPa (abs).

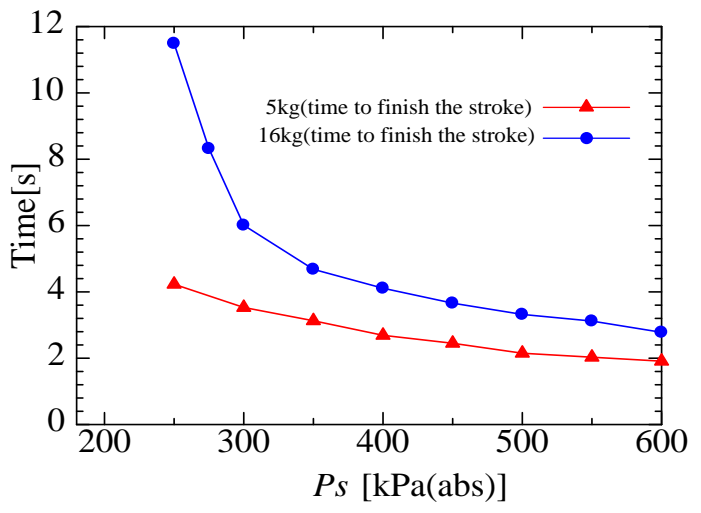

Figure 12. Relationship between supply pressure and reaching time. 


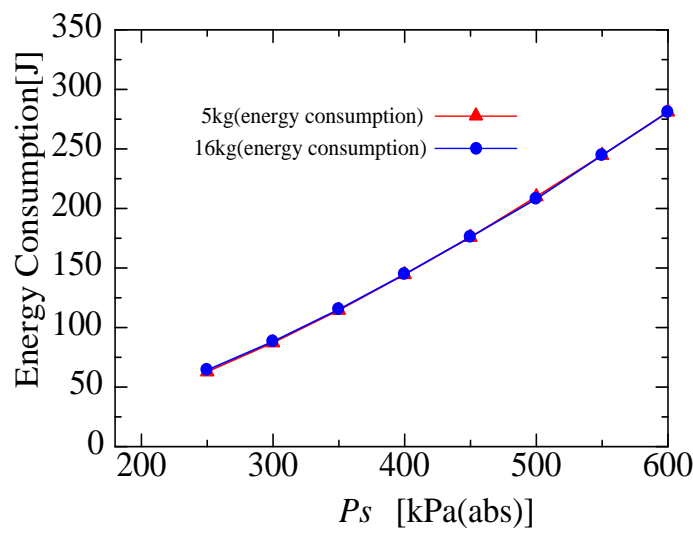

Figure 13. Relationship between supply pressure and energy consumption.

\section{Conclusions}

This paper showed experimental results of air transmission and energy consumption in pneumatic cylinder system by using air power meter. Experimental results showed:

1) Energy consumption is not relevant to the mass of load. It is mostly relevant to the supply air pressure.

2) The energy consumption in meter-out circuit is almost the same as in meter-in circuit.

3) There is approximately $30 \%-40 \%$ energy loss occurs in this experiment. It is considered that the reasons are orifice, piston friction and acceleration.

4) In meter-out circuit, over $80 \%$ of power is used for the control of velocity.

With the assessment of energy consumption established, the quantification of energy transmission in pneumatic cylinder system will be realized. It is expected to be useful for energy saving research.

\section{References}

[1] Shi, Y.X., Li, X.N. and Teng, Y. (2005) Research on Pneumatic Cylinder's Exhausted-Air Reclaiming Control Devices. Proceedings of the JFPS International Symposium on Fluid Power, Tsukuba, 7-10 November 2005, 558-563.

[2] Cai, M.L., Fujita, T. and Kagawa, T. (2001) Energy Consumption and Assessment of Pneumatic Actuating Systems. Journal of The Japan Fluid Power System Society, 32, 118-123.

[3] Cai, M.L., Fujita, T. and Kagawa, T. (2002) Distribution of Air Available Energy in Pneumatic Cylinder Actuation. Journal of the Japan Fluid Power System Society, 33, 91-98. http://dx.doi.org/10.5739/jfps.33.91

[4] Cai, M.L. and Kagawa, T. (2007) Energy Consumption Assessment and Energy Loss Analysis in Pneumatic System. Chinese Journal of Mechanical Engineering, 43, 69-74. http://dx.doi.org/10.3901/JME.2007.09.069

[5] Li, K.W. (1995) Applied Thermodynamics: Availability Method and Energy Conversion. Taylor \& Francis, London.

[6] Cai, M.L., Kawashima, K. and Kagawa, T. (2006) Power Assessment of Flowing Compressed Air. Journal of Fluids Engineering, Transactions of the ASME, 128, 402-405. 
Scientific Research Publishing (SCIRP) is one of the largest Open Access journal publishers. It is currently publishing more than 200 open access, online, peer-reviewed journals covering a wide range of academic disciplines. SCIRP serves the worldwide academic communities and contributes to the progress and application of science with its publication.

Other selected journals from SCIRP are listed as below. Submit your manuscript to us via either submit@scirp.org or Online Submission Portal.
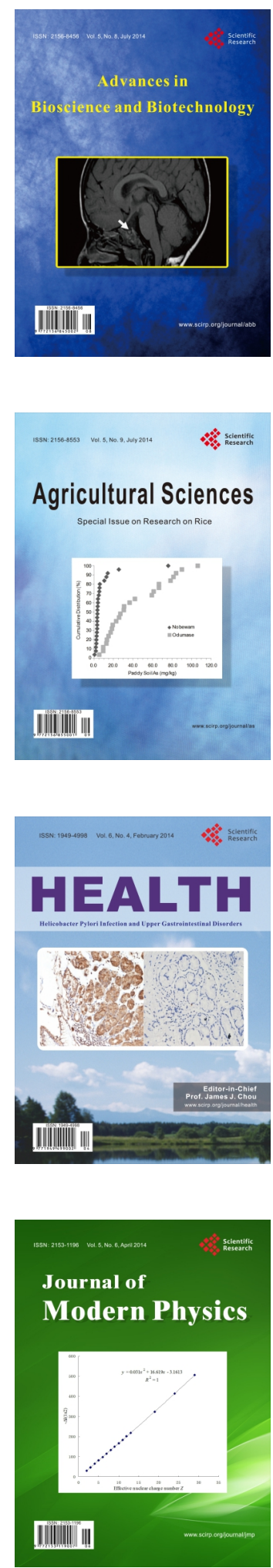
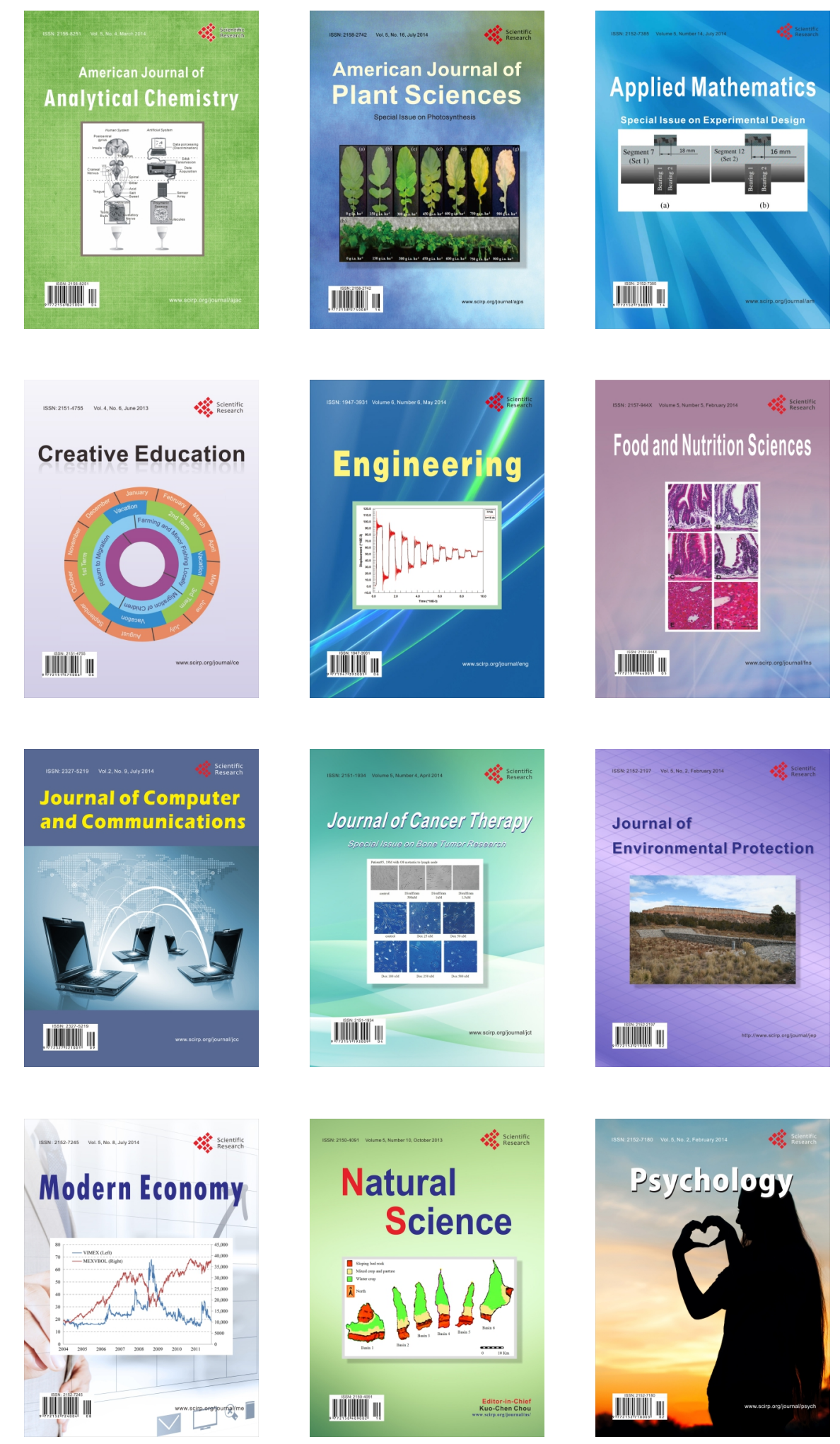